\title{
LA FICCIONALIZACIÓN DEL DETERIORO EN LA NARRATIVA VENEZOLANA
}

\author{
POR \\ JUDIT GERENDAS \\ Universidad Central de Venezuela
}

Llama la atención del lector de la narrativa venezolana contemporánea el hecho de que el problema del pasado y de la modernidad atraviesa intensamente, y con gran fuerza dramática, a esta narrativa, desde finales del siglo XIX hasta nuestros días inclusive. Dentro del amplio registro que abarca esta perspectiva, en una cierta línea de la literatura venezolana, y no en toda ella, claro está, podemos rastrear una reiterada presencia de la confrontación entre ciudad y naturaleza, en la cual encontraremos algunas veces - aunque no siempre con la misma connotación- una visión idílica en relación al campo y una imagen degradada en cuanto a la representación de la ciudad. Sin detenernos en los antecedentes del siglo pasado, tales como "Costumbres de Barullópolis", de Fermín Toro, Todo un pueblo, de Miguel Eduardo Pardo y Peonía, de Romero García, podemos observar que ya en la novela Idolos rotos, en 1901, de Manuel Díaz Rodríguez, la ciudad representada, Caracas, surge como un espacio que el protagonista, Alberto Soria, considera" estrecha y mezquina de conciencia, como sus calles, angosta y sucia". ${ }^{1}$ La Plaza Bolívar, que luego tendrá también un papel fundamental en la narrativa de Guillermo Meneses y en la de Salvador Garmendia, es el escenario en el que tienen lugar, en esta novela, los encuentros en los que se pactan las componendas, las traiciones y la corrupción, e incluso recibe el siniestro calificativo de "pedazo de tierra maldito, como un pudridero de conciencias"(91).

La representación de la ciudad adquiere carácter paradigmático en las primeras novelas de Salvador Garmendia, en particular en Los pequeños seres (1959), Los habitantes (1961), Día de ceniza (1963) y La mala vida (1968), las cuales se constituyen en brillante ficcionalización de la desaparición de la ciudad tal como había sido hasta los años cincuenta de nuestro siglo, así como de su demolición y reconstrucción, hechos que dieron paso a una modernidad que irrumpía arrastrando tras de sí el desarraigo, la dislocación y los desencuentros.

En una ciudad hostil se mueven los personajes garmendianos, sin memoria, sin futuro, degradados, cosificados y alienados, en un mundo signado por lo sórdido y lo banal. El desmoronamiento y la descomposición se instalan en un espacio en el que se va fundando

\footnotetext{
${ }^{1}$ Manuel Díaz Rodríguez. Idolos rotos. En Narrativa y ensayo. Selección y prólogo de Orlando Araujo (Caracas: Biblioteca Ayacucho, 1982) 92.
} 
la nada. En Día de ceniza nos encontramos con que la suciedad y la basura abarcan también al carnaval mismo, esa fiesta popular que Bajtín definía como de carácter utópico y benéfico. En esta novela los personajes se valen de máscaras, a las que pretenden convertir en mediadores imaginarios entre su yo amorfo y la realidad opaca y carente de atractivo. En la línea de los personajes de Guillermo Meneses - en sus cuentos y novelas, que abarcan un período tan considerable como el que se extiende entre 1931 y 1961 - con la ayuda de sus disfraces intentan diseñar una ceremonia que les permita realizarse. Pero ni siquiera así lograrán dibujar un contorno definido que sustituya eficazmente sus rostros desdibujados. Es el carnaval el momento privilegiado que escogen para intentar dar respuesta a su informe anhelo de subvertir la mediocre realidad cotidiana y alcanzar otro orden de existencia. Sin embargo, en vez de establecerse, como en la tradición festiva, una oposición entre lo alto y lo bajo, entre la vida institucionalizada y los valores populares que irrumpen por medio de la farsa y el disfraz, lo que se extiende por todos los intersticios es la podredumbre y la corrupción, tanto del mundo material como del espíritu. El aturdimiento del alcohol termina sustituyendo la celebración carnavalesca auténtica.

El quehacer aparentemente sin sentido de los personajes, sin objetivos individuales o colectivos, sin algún tipo de coherencia, se continuará en una línea importante de la narrativa venezolana contemporánea y tendrá uno de sus representantes más notables y recientes en Adiós gente del sur (1991), de Orlando Chirinos. Pero si en vez de buscar la línea de continuidad hacia adelante, indagáramos por las relaciones que pueden establecerse con este tipo de ficcionalización en textos anteriores, indudablemente tendremos que encontrar un umbral significativo en los poemas en prosa - ¿o prosa poética? - de José Antonio Ramos Sucre, quien en sus breves y esplendorosos escritos hace fulgurar, a través de figuras apenas esbozadas, la soledad y la incomunicación como características primordiales de sus personajes.

En País portátil (1968), de Adriano González León, el trepidar de la ciudad moderna se opone a una visión no idílica, pero claramente diferenciada, del pasado patriarcal de las montañas andinas, espacio de un mundo caudillesco y varonil que se hunde y desmorona, pero también de otro femenino, levemente cursi y bobalicón, signado por la ingenuidad y la ignorancia y la frustrada ilusión de poder vivir algo más hermoso que la existencia estrecha y mezquina que ofrecía la realidad ficcionalizada.

El tráfago, la velocidad y el movimiento le imprimen un ritmo propio al lenguaje de País portátil, en el que aliteraciones, imágenes y onomatopeyas intensifican el efecto de agresión, de penetración y de caos. La ciudad es el escenario del ruido, de la violencia, de la contaminación, la podredumbre y la fragmentación. Un mundo urbano convertido en imágenes y sonido, en sonido y furia, en un espacio que bien podría ser el del idiota mencionado por Macbeth y novelizado por Faulkner. Es la ciudad del azar, de la fugacidad del tiempo, de la carencia de raíces, de la discontinuidad: es una ciudad portátil, metonímicamente representada en ese billete de lotería que se vocea con el grito de “¡Caracas, para hoy, suma trece!”: ciudad de la fortuna fácil, de la eventualidad y la contingencia. Una ciudad amorfa y caótica, sin principio ni fin.

En oposición a ellạ, el mundo rural de la provincia no ofrece tampoco una visión idílica, como ya dijimos, sino una imagen de deterioro y de ruina, de un tiempo detenido y unas vidas humanas devastadas, en el que los elementos que configuraban el hogar, el espacio 
para la vida, están siendo destruidos, lenta pero inexorablemente, por millares de polillas, comejenes y cucarachas.

La carencia y la desposesión que caracterizan al presente se contraponen a las magníficas figuras de los retratos familiares, testigos mudos de la decadencia y del desmoronamiento. Pero es importante subrayar que el esplendor del pasado ya sólo se conserva en imágenes y ha dejado de tener un efecto dinamizante y vivificante sobre el presente. Se mantiene detenido en el tiempo y en el espacio, dentro del breve marco de las inmóviles fotografías.

La ficcionalización de la modernidad urbana en País portátil no toma cuerpo solamente en el plano temático y en el del lenguaje, sino que adquiere funciones también en el de la composición, al estructurarse los capítulos o apartes correspondientes a la ciudad a partir del movimiento de arranque y de frenada de las largas hileras de vehículos que se desplazan a la vez por el espacio de la ciudad y el del texto. El punto de vista narrativo se sitúa en el interior de los diversos vehículos por los que viaja el protagonista, a partir de cuya mirada vemos el mundo de afuera, que es el que pasa, observado desde adentro. La mirada está encerrada en un lugar limitado y el mundo pierde parcialmente sus contornos a causa de la velocidad del vehículo. Sólo percibimos lo que el personaje ve desde su incómodo puesto en el autobús o el automóvil. Por otra parte, los individuos también pierden los rasgos que los delimitan como tales y se convierten en un todo homogéneo, en el ámbito cerrado del tráfico de la ciudad.

En Adiós gente del sur ${ }^{2}$ nos encontramos con ciertos significados que pueden considerarse dentro de la misma línea narrativa esbozada, aunque con importantes variantes, también. Aquí parecería completarse la ficcionalización de la nada iniciada en la novelística de Salvador Garmendia. El mundo representado se nos muestra ahora mucho más indiferenciado y el tiempo del relato se funde en uno solo, indiscriminado. Al mismo tiempo, la referencialidad histórica, tan marcada en País portátil, en Adiós gente del sur tiende a desaparecer, sugiriendo que el proceso mismo de la historia se ha abolido.

El campo, en esta novela, también se representa sin bucolismo alguno. Los objetos del mundo se perciben de una manera amorfa, amenazante. El desmoronamiento está instalado en el centro de la narrativa y el paso de los años sólo conlleva deterioro y ausencia de calor humano.

Como su nombre lo indica, la novela es una despedida, de gente que ya pasó, que ya no existe. Se recrea su historia, así como la del protagonista, viejo y derrotado, a partir de fotografías que dan lugar a las asociaciones de ideas y a las evocaciones del personaje. Es interesante observar que el recurso temático de utilizar fotografias como desencadenantes de diversas vertientes de la acción narrativa fue utilizada también, con gran eficacia, por Luis Britto García en su novela Abrapalabra (1980), así como por Igor Delgado Senior en su cuento "Instantes de una pasión inútil" (1989) y, como ya vimos, de algún modo también se encuentra presente en País portátil.

El mundo entero está contaminado en Adiós gente del sur, tanto la naturaleza como los espacios construidos por el hombre. El quehacer humano fatalmente está condenado a la gratuidad. El protagonista no ha logrado asir nada de la existencia, no logra fijar una

\footnotetext{
${ }^{2}$ Orlando Chirinos. Adiós gente del sur (Caracas: Alfadil, 1991) 17. A continuación se cita en el texto
} el número de página por esta edición. 
permanencia en nada. Ha quedado flotando al margen, desarraigado y desamparado, soñando con objetos devaluados que ni siquiera merecen la pena ser soñados y que ya ni a los sueños pueden otorgar grandeza.

También el pasado está constituido por imágenes de deterioro, como por ejemplo las "telas desinfladas colgando fláccidamente de las paredes", ${ }^{3} \mathrm{y}$ el olor a orín viejo que germina de las esquinas con el viento (21). Se crea una atmósfera de elementos en descomposición, de podredumbre y corrupción.

El deterioro generalizado y universal en esta novela lleva al personaje a intentar estar en una condición que podríamos denominar de extrañamiento, de estar fuera de sí, para así poderse observar a sí mismo y tomar distancia, para lograr de alguna manera abandonar la existencia e instalarse en la nostalgia.

Desintegrado, amputado, Gregorio, el protagonista, se considera a sí mismo hecho de un "costraje nostálgico", de "capas delgadas ... construidas en diferentes lugares y épocas" (44). Esta idea temática central se halla en correspondencia muy lograda con el modo de construcción del texto, hecho a su vez por niveles de evocación, anticipaciones y regresiones, en ese estrato temporal que he señalado como indiscriminado. El recuerdo que parte desde un presente de vejez, en arco tendido hacia el pasado remoto, abarca en su espacio los diálogos, la narración y la descripción.

A partir de la vestimenta de los individuos retratados, el personaje evoca y reconstruye el pasado. Con melancólica ternura y leve ironía, mira a los seres que se fotografiaron para una posteridad que él sabe cancelada, y constata que las poses de alegría o de felicidad sólo pudieron ser fingidas. Son símbolos de la vida detenida y deteriorada y, como las imágenes en Abrapalabra, de Luis Britto García, se interponen, como mediadores, entre lo real y su percepción, constituyéndose en vehículo de la abolición del conocimiento.

El color gris predomina en Adiós gente del sur, al igual que en La danza del jaguar, de Ednodio Quintero, también de 1991. En esta última encontramos un río color pizarra", "una laja cenicienta" (11), "sombras danzantes en la hierba color suero" (12), y los hombres que llegan para matar al padre del protagonista llevan "largos gabanes color plomo" (26).

La oscuridad, a su vez, en Adiós gente del sur se vincula con la nostalgia del pasado, con los viejos cuartos "rellenos de oscuridad azulina, olorosos a rastros picantes de humo o a vahos amentolados. ${ }^{5}$ La falta de luz, la opacidad, la oscuridad, la parálisis, la vida detenida y el deterioro connotan la historia relatada. La oscuridad lo abarca y lo ocupa todo, penetra la vida y hasta los árboles son negros y amenazantes.

En esta novela el pasado no permite que el individuo crezca y se haga adulto, que tenga vida propia y que sea capaz a la vez de mantener las raíces y de separarse e independizarse. El impulso incontenible del personaje es hacia la búsqueda de un pasado, el cual, sin embargo, ya está caduco e inerte, es decir, no es un pasado vivificante y germinal, sino algo siniestro que tiene al personaje atrapado. El individuo aparece en la novela alienándose de su propio espacio para terminar por sumergirse en un túnel que lo aprisiona, que no le permite una existencia autónoma y libre.

\footnotetext{
${ }^{3}$ Adiós gente del sur 17.

${ }^{4}$ Ednodio Quintero. La danza del jaguar (Caracas: Monte Ávila, 1991) 11. A continuación se cita en el texto el número de página por esta edición.

${ }^{5}$ Adiós gente del sur 16.
} 
El pasado se convierte de esta manera en una atemorizante fuerza que se ha independizado y que ejerce una influencia que escapa al control del individuo.

La construcción de Adiós gente del sur es sumamente compleja y podríamos quizás compararla con el funcionamiento de un caleidoscopio: la narración va girando, desplazándose imperceptiblemente, y cada vez surgen nuevos matices, nuevas visiones, que se funden, se complementan y se contradicen.

Si intentáramos definir el campo de las actividades discursivas con las cuales se corresponden estos discursos literarios, creo que tendríamos que encontrar relaciones significativas con aquellos enunciados sociológicos, económicos o históricos que nos hablan de una irrupción violenta de la producción petrolera, que se establecióyuxtaponiéndose a una formación social agraria y a unas modalidades de existencia básicamente rurales, provocando un corte brusco e inesperado que de pronto abolió tradiciones, ritmos vitales, creencias y valores, para insurgir explosivamente, aboliendo también el tiempo necesario para crearse sus propias raíces y constituir sus propias formas de existencia, dando origen a un sistema social y a una cultura caracterizados literalmente por el desarraigo, por la carencia de esas raíces que no podían surgir de la nada.

Ahora bien, este corte epistemológico puede resultar interesante y productivo, pero evidentemente no es suficiente. Específicamente por el hecho concreto de que antes ya de la omnipresencia del petróleo en todos los aspectos de la historia venezolana, existieron textos narrativos, tal como hemos mencionado, en los que el universo ficticio se estructuraba en torno a los grandes interrogantes acerca del pasado y la tradición, por una parte, y la modernidad y el progreso, por la otra. Había una nostalgia desde antes, y la mirada que se tornaba hacia un pasado extraviado, inalcanzable, configuraba la perspectiva desde la cual la narración se producía.

Entonces, si intentamos trazar el corte epistemológico en otro lugar y otro momento, quizás podríamos encontrar, siguiendo en parte las teorías de Foucault, ${ }^{6}$ un haz de relaciones y un conjunto de dispersiones, entre los cuales tendríamos que describir las actividades discursivas que se produjeron en el campo de la historiografía en torno a la extrema violencia que se desató en Venezuela a lo largo de todo el siglo XIX, desde los inicios mismos de la guerra de emancipación hasta las últimas luchas caudillescas, pasando por la guerra de la federación, todas las cuales tuvieron la característica fundamental de producir el exterminio o la emigración de gran parte de las clases pudientes, de devastar el país y de dar origen a una gran movilidad en las clases sociales, todo lo cual trajo también como consecuencia la ruptura de las tradiciones y el desarraigo, sin lograrse fundar espacios culturales alternativos suficientemente estables.

En relación a esta situación puede resultar paradigmática, en numerosos textos narrativos significativos, la tematización en torno a papeles viejos, a documentos de propiedad ya carentes de valor, pero a los cuales los personajes se aferran patéticamente, como a símbolos de una grandeza pasada que ha sido sustituida por la marginalidad. En este sentido puede mencionarse también a País portátil, novela en la cual el personaje Abuelo, viviendo la decadencia de su casa y de su cuerpo, rememora las pérdidas sufridas y los despojos, mientras saca cuentas y revisa documentos legales ya sin valor alguno. Gran parte

${ }^{6}$ Michel Foucault. La arqueología del saber (México: Siglo XXI, 1970). 
del discurso de este personaje, incluso cuando se refiere a temas por completo ajenos a la cuestión legal - asuntos familiares, amorosos, etc. - se construye mediante giros, sintaxis y vocabulario que pertenecen al discurso de tipo jurídico.

El mundo que alguna vez fue esplendoroso o el que llegó a ser apenas "existente", pero que se representa desde el recuerdo como espacio definible como tal, se nos muestra en Alacranes (1968), de Rodolfo Izaguirre, en las novelas de Salvador Garmendia, en País portátil y en Adiós gente del sur, entre muchos otros, como mundos que literalmente fueron devorados por pequeños animales que con infinita paciencia roen la materia hasta acabar con ella. De esta manera nos vamos a encontrar con que el espacio narrativo - recurso de composición- y el mundo representado son recorridos simultáneamente por ratones, comejenes, hormigas, chinches, cucarachas y otras alimañas de este tipo, los cuales se convierten en vehículo del desgaste y del desmoronamiento.

La naturaleza misma termina mostrándose, contrariamente a su imagen de fecundidad tradicional, como el mundo de la esterilidad, tal como lo podemos observar en La danza del jaguar, en la que encontramos, junto a un suelo quemado, "un bosque ralo de arbustos retorcidos, ramas sarmentosas y troncos ennegrecidos como carbón" (11). En Adiós gente del sur los rasgos del sol son "macilentos" y la luz que emiten es "escurridiza", en franca inversión y subversión de la adjetivación luminosa y cálida que tradicionalmente califica a este astro.

En la reciente novela de Ana Teresa Torres, El exilio del tiempo (1990), un ejemplo claro de degradación lo podemos encontrar en relación con la champaña, la bebida que por excelencia es símbolo de alegría y de lujo y, por metonimia, de efervescencia: aquí se ha convertido en un "caldito insípido, residuo de una champaña bien helada de la que han huido las burbujas y el encanto ...".7 Pero no es sólo la bebida la que se ha vuelto algo mediocre, son los tiempos mismos los que se han convertido en un remedo del pasado, en una visión en la que, una vez más, la narrativa venezolana retoma con voz nueva el torturante antagonismo que se percibe entre un presente sentido como inauténtico y un pasado imaginado como verídico. El presente representado es mostrado como una falsificación, una imitación tramposa y poco lograda de un mundo pasado que, en este caso, al igual que en la novela siguiente de la autora, Doña Inés contra el olvido (1992), se presenta francamente aristocrático y de abolengo.

Por otra parte, hay aún otro haz de relaciones significativo en cuanto a la narrativa que estamos revisando. Se trata de aquéllas vinculadas con las inmensas expectativas que surgieron en el país a partir de 1958, fecha de la caída de la dictadura de Pérez Jiménez, y del inicio de un extraordinario auge de masas, que surgió al calor de las acciones populares y de la movilización que se llevó a cabo en esos primeros años de la democracia, en torno a un conjunto de aspiraciones colectivas. El estrecho vínculo con la Revolución Cubana y la presencia de Fidel Castro en Caracas, con una participación popular multitudinaria, jugaron también un papel de primer orden en la conformación de una situación revolucionaria. El triunfo electoral de Rómulo Betancourt en 1959 y luego su gobierno fueron clausurando las alternativas que se basaban en estas expectativas y condujeron a la frustración de las aspiraciones de cambio de grandes mayorías. La lucha armada que se desarrolló como consecuencia de todas estas circunstancias generó a su vez nuevas ilusiones y esperanzas,

${ }^{7}$ Ana Teresa Torres, El exilio del tiempo (Caracas: Monte Ávila, 1990) 11. 
pero su derrota un par de años después condujo a una situación de frustración, desánimo, escepticismo e inercia. Dentro de la formación discursiva que estamos analizando ello se constituye en uno de los elementos significativos dentro del proceso de producción de esta narrativa, aunque no aparezca de manera directa dentro de la misma.

En Adiós gente del sur, por ejemplo, se percibe que el propio hecho de vivir conlleva ya la derrota, y que todo quehacer humano será, a fin de cuentas, inútil. La no pertenencia a nada que se observa en esta novela lleva al personaje principal a la pérdida de sí mismo y a la carencia de autoestima. Lo que se ficcionaliza es la extinción, la desaparición, la conversión en sombra, en pasado, en recuerdo, en memoria. También el pasado está constituido por imágenes de deterioro. El mundo entero está sometido a un proceso de destrucción, de desmoronamiento y de ruina y lo que se ficcionaliza -en logro notablees el paso del tiempo, el proceso de la descomposición, el movimiento del abandono, la imagen de la parálisis ahistórica, el desgaste físico, el malestar, el envejecimiento y la caducidad. El ser humano representado adquiere una condición fantasmal y la presencia dominante en el universo ficticio se traslada a los animales invasores que producen degradación y deterioro.

En la novela de Orlando Chirinos es la luz el vehículo de la uniformización, el umbral que lleva a la parálisis, a una vida sólo aparente, vaciada de contenido: "El último sol de la tarde les igualó los rostros en un tono ladrillo, y ellos se quedaron como tres cosas sin vida, paralizados, con miedo a tocar en la puerta o a hablar". ${ }^{8}$

Los fantasmas y los recuerdos atraviesan la narración, en una búsqueda incesante que no conduce a nada, que pareciera realizarse en círculos que se repiten eternamente y para la cual la posibilidad misma de un hallazgo pareciera estar clausurada.

Es la carencia y la desposesión, el deterioro y la decadencia, insertos en el horror del sin sentido. La soledad, la incomunicación, seres y mundos devastados y carcomidos, espacios que se desmoronan y tiempos que desaparecen son los núcleos semánticos de esta novela, en la que se logra crear con especial maestría una atmósfera de podredumbre, de elementos en descomposición, de corrupción de la materia orgánica; en este contexto se expresa la náusea que produce una condición humana banalizada y mediocre.

Dentro de esta situación de malestar en el presente, el protagonista de Adiós gente del sur revisa una foto tras otra, pero también las imágenes del pasado, las fotografias, estarán deterioradas.

No es muy diferente la situación del futuro en La danza del jaguar, en la que, en cuestión de segundos, el personaje adolescente, en el pasillo del Liceo, vislumbra el porvenir como el lugar del deterioro, de la vejezy de la muerte. El juvenil protagonista tiene una imagen del futuro triste y melancólica, en un mundo en el que, evidentemente, la posibilidad de inventar utopías ya se ha perdido. El porvenir es temible y miserable, con rasgos de ciencia-ficción o de una anti-utopía.

En muchas de estas novelas la anécdota es escasa: lo que interesa es la tensión que expresa una situación en el mundo, una perspectiva, un asedio a través del lenguaje y de la composición. Se ha asordinado el suspenso argumental en aras de la intensidad de la percepción y de la representación; se ha abandonado la aspiración a una concepción armónica en la cual la narrativa anterior, en gran medida, todavía había seguido confiando,

${ }^{8}$ Adiós gente del sur 38. 
incluso cuando describía la violencia o lo abyecto; ahora la narrativa, o al menos la línea que estamos revisando, insurge con una visión desde la posición del antihéroe, a través de elementos triviales, que generan significado a partir de su escasa significación.

Los críticos se han preguntado reiteradas veces acerca de qué país expresa nuestra literatura, ya que su vocación de tomar a Venezuela como su referente fundamental es evidente.

Yo pienso que nuestra literatura da una imagen y una representación del mundo venezolano, a través de la palabra y del diseño de la obra y a través del intento de reconstruir y de dar cuerpo a una memoria fragmentada y dispersa, elusiva, marginada por fuerzas históricas que muchas veces irrumpieron violenta y arbitrariamente. Al mismo tiempo, ha ficcionalizado el proceso mismo del escamoteo y del intento de reconstrucción y se ha constituido en espacio privilegiado para representar, a través del imaginario literario, la frustración y la derrota como vivencias auténticas. Se constituye en una visión peculiar de la modernidad, del progreso y del mundo contemporáneo, en una evocación del pasado remoto que se percibe como un tiempo fantasmagórico. La temporalidad es problemática fundamental de esta narrativa, que se desplaza por el tiempo hecho materia ficcional en múltiples sentidos, o se ancla en él, atrapado en su presunta parálisis, o avanza en círculos, repitiendo sus pasos sin cesar. Lo trágico y lo grotesco se aúnan en esta novelística, en la cual los límites del género se difuminan, y novela, memoria y prosa poética se interpenetran a través de soliloquios, diálogos, descripciones, evocaciones, sueños y ensoñaciones. Se reitera la aseveración de la inutilidad de los actos y de la imposibilidad de reencontrar los vínculos con un pasado que se busca con insistencia, una y otra vez, de manera obsesiva, pero que termina convirtiéndose en algo inasible, intensamente solicitado, pero aparentemente irrecuperable, debido a que un presente que se percibe degradado y en constante desmoronamiento, se interpone tenazmente entre el sujeto del discurso y ese espacio contradictorio e inalcanzable. 